\title{
Natal and Neonatal Teeth in Relation to Environmental Toxicants
}

\author{
SATU ALALUUSUA, HANNU KIVIRANTA, ANU LEPPÄNIEMI, PÄIVI HÖLTTÄ, \\ PIRJO-LIISA LUKINMAA, LEENA LOPE, $\dagger$ ANNA-LIISA JÄRVENPÄÄ, MARTIN RENLUND, \\ JORMA TOPPARI, HELENA VIRTANEN, MARKO KALEVA, AND TERTTU VARTIAINEN \\ Department of Pedodontics and Orthodontics, Institute of Dentistry, University of Helsinki, Finland [S.A., \\ A.L., P.H.]; Department of Oral and Maxillofacial Diseases, Helsinki University Central Hospital, \\ Helsinki, Finland [S.A., P.H.]; National Public Health Institute, Department of Environmental Health, \\ Kuopio, Finland [H.K., T.V.]; Department of Oral Pathology, Institute of Dentistry, University of Helsinki, \\ and Department of Pathology, Helsinki University Central Hospital, Helsinki, Finland [P-L.L.]; Jorvi \\ Hospital, Espoo, Finland [L.L.]; Hospital for Children and Adolescents and Department of Obstetrics, \\ Helsinki University Central Hospital, Helsinki, Finland [A-L.J., M.R.]; Departments of Physiology and \\ Pediatrics, University of Turku, Turku, Finland [J.T., H.V., M.K.]; and Department of Environmental \\ Sciences, University of Kuopio, Kuopio, Finland [T.V.]
}

\begin{abstract}
Infants born to mothers heavily exposed to polychlorinated biphenyls (PCBs) and dibenzofurans (PCDFs) have earlier been reported to have increased prevalences of natal and neonatal teeth. Some tendency toward higher prevalence figures of natal and neonatal teeth can be seen in the literature in normal child populations during the last $40 \mathrm{y}$. We therefore decided to determine the present prevalence of these teeth in a Finnish population and to evaluate whether infants with natal and neonatal teeth are more exposed to PCBs, PCDFs, and polychlorinated dibenzo- $p$ dioxins (PCDDs) than infants on average. A total of 34,457 infants born in 1997-2000 in four hospitals in southern Finland were examined for natal and neonatal teeth. The exposure of the infant to PCBs and PCDD/Fs was evaluated by measuring the levels of 17 most toxic PCDD/F and 36 PCB congeners in his or her mother's milk sample when the child was $4-8$ wk old. A total of 34 infants had one or two natal (29 infants) or neonatal teeth (five infants). The milk analyses showed that the median level of PCDD/Fs as toxic equivalent (World Health Organization-recommended 2,3,7,8-tetrachlorodibenzo- $p$-dioxin equivalent quantity for $\mathrm{PCDD} / \mathrm{Fs}$ in fat) was $11.9 \mathrm{pg} / \mathrm{g}$ in fat, and that
\end{abstract}

ABSTRACT

of PCBs (World Health Organization-recommended 2,3,7,8tetrachlorodibenzo- $p$-dioxin equivalent quantity for PCBs) was $7.24 \mathrm{pg} / \mathrm{g}$ in fat. These levels corresponded to the prevailing levels. The results showed that the prevalence of natal and neonatal teeth was 1:1000. No association was found between pollutant levels and occurrence of natal and neonatal teeth, indicating that the prevailing levels of PCDD/Fs and PCBs are likely to be below the threshold to cause perinatal eruption of teeth. (Pediatr Res 52: 652-655, 2002)

Abbreviations
PCB, polychlorinated biphenyl
PCDF, polychlorinated dibenzofuran
PCDD, polychlorinated dibenzo- $p$-dioxin
TCDD, 2,3,7,8-tetrachlorodibenzo- $p$-dioxin
WHO
TCDD equivalent $-\mathbf{T E q}$, World Health Organization-recommended
WHO $_{\mathbf{P C B}}$-TEq, World Health Organization-recommended
TCDD equivalent quantity for PCBs

Normally, primary teeth begin to erupt at approximately 6 mo of age. In rare cases, the chronology of tooth eruption is significantly altered, and the first teeth are present at birth or will emerge shortly after birth. By definition the teeth that are

Received February 8, 2002; accepted June 17, 2002.

Correspondence: Satu Alaluusua, D.D.S., Department of Pedodontics and Orthodontics, Institute of Dentistry, P.O. Box 41, 00014 University of Helsinki, Finland; e-mail: satu.alaluusua@helsinki.fi

Supported by the Academy of Finland, Finnish Research Program on Environmental Health, (Contract 43353) and the European Commission (Contract QLK4-1999-01466). $\dagger$ Deceased.

DOI: 10.1203/01.PDR.0000031926.09665.F1 present at birth are called natal teeth and those which erupt within a month after delivery are neonatal teeth (1). Almost always these teeth occur in the region of the mandibular central incisor (1-5). Approximately $90 \%$ of them are primary teeth and $10 \%$ are supernumerary teeth $(1,3,5,6)$.

The reported prevalences of natal and neonatal teeth in a normal population have varied considerably from 1 in 11 to 1 in 30,000 births (7). Early prevalence studies from 1876 to 1958 reviewed by Bodenhoff and Gorlin(8) showed that among the 16 studies included the median prevalence was 1 in 6000 births. Among six later studies published between 1967 and 
1991 the median prevalence values were 1 to 1442 and 1 to 1118 (3-5, 9-11). Although the condition has always been very rare, there seems thus to be a slight tendency toward higher prevalences during the last $40 \mathrm{y}$.

The cause of natal or neonatal teeth in a normal child population is unclear, although it has been reported to be related to the superficial position of the tooth germ $(3,8,12$, $13)$ and to heredity $(1-3,8,10)$.

The only environmental factor that may be regarded as a causative factor of natal teeth is the toxic polyhalogenated aromatic hydrocarbons: PCBs, PCDDs, and PCDFs. They are among the most widespread environmental pollutants. They cross the placenta $(14,15)$, and concentrations of PCDD/Fs in the adipose tissue of a newborn are correlated with those in mother's milk (16). Every 10th infant born to mothers who were heavily exposed to PCBs and PCDFs in an environmental accident in Taiwan (the so-called Yusheng accident) had natal teeth $(17,18)$. Similar reports were obtained from another environmental accident that took place in Japan (the so-called Yusho accident) $(19,20)$. Experimental studies support these human observations. Accordingly, it has been shown that exposure to TCDD, the most toxic of PCDD congeners, causes premature eruption of the continuously erupting lower incisor teeth in mice (21).

The purpose of the present study was to determine the prevalence of natal and neonatal teeth in southern Finland and to see whether children with natal or neonatal teeth are exposed to higher levels of PCB or PCDD/F compounds than children on average.

\section{METHODS}

Subjects. All newborn children in four hospitals (Jorvi Hospital; Departments of Obstetrics and Gynecology, Helsinki University Central Hospital; Helsinki City Maternity Hospital; and Turku University Central Hospital) located in Helsinki and the Turku area, southern Finland, were examined for natal and neonatal teeth by pediatricians during a period varying from 1.5 to $2.8 \mathrm{y}$. The children were born in 1997-2000. The mothers of identified children and three control mothers for each identified child in the Turku area were asked for their willingness to participate in the study. If willing, the mothers were contacted 2 to $3 \mathrm{wk}$ later and asked to collect a milk sample of approximately $200 \mathrm{~mL}$ when the child was approximately 4-8 wk old. The bottle for collection was provided. Those mothers who had a child with expected neonatal tooth were contacted by phone once more for confirmation of the eruption time of the tooth.

The study design was approved by the Human Research Ethics Committee of the Faculty of Medicine, University of Turku. All but two mothers of identified cases were willing to participate the study. A written consent was obtained from the mothers for the analyses of the milk samples.

Analyses of PCBs and PCDD/Fs in mother's milk. As a proxy for the transplacental exposure, the level of PCBs and PCDD/Fs was estimated in milk. The 17 most toxic PCDD/F and 36 PCB congeners were measured by gas chromatography-high-resolution mass spectrometry $(22,23)$. The labora- tory is an accredited testing laboratory (No. T077) in Finland (EN ISO/IEC 17025). The scope of accreditation includes PCDD/Fs and PCBs from human milk samples. The values were given in World Health Organization-recommended TCDD equivalent quantities: $\mathrm{WHO}_{\mathrm{PCDD} / \mathrm{F}^{-}}$TEqs and $\mathrm{WHO}_{\mathrm{PCB}^{-}}$ TEqs (24).

The differences in the milk $\mathrm{WHO}_{\mathrm{PCDD} / \mathrm{F}^{-}}-\mathrm{TEq}$ and $\mathrm{WHO}_{\mathrm{PCB}^{-}}$ TEq concentrations between the test samples (natal and neonatal milks) and the control samples obtained from Turku area and between test samples obtained from Turku and Helsinki areas were assessed by Mann-Whitney $U$ test.

\section{RESULTS}

Prevalence. From a total of 34,457 newborns 29 had natal teeth. The pediatricians had recorded neonatal teeth in eight children after the birth. In five of these eight children, the teeth erupted within a month after delivery, being true neonatal teeth. The prevalence for natal teeth was thus 1:1188 and for natal and neonatal teeth $1: 1013$.

The 34 infants had 47 natal and eight neonatal teeth. Twenty-two $(65 \%)$ had a pair of teeth and the remainder a single tooth. In all cases the teeth were located in the region of mandibular central incisors.

Milk PCDD/Fs and PCB concentrations. A total of 14 mothers having a child with natal or neonatal teeth (11 mothers from the Helsinki area and three mothers from the Turku area) and 12 control mothers (from the Turku area) where able and willing to give a milk sample. The median concentration of

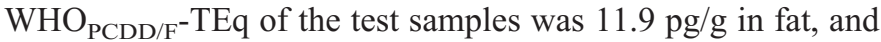
that of $\mathrm{WHO}_{\mathrm{PCB}}-\mathrm{TEq} 7.24 \mathrm{pg} / \mathrm{g}$ in fat. Corresponding 25 th and 75th percentiles were 7.02, 14.1 and 4.55, 9.54, respectively. No significant differences in $\mathrm{WHO}_{\mathrm{PCDD} / \mathrm{F}^{-}}-\mathrm{TEq}$ and $\mathrm{WHO}_{\mathrm{PCB}^{-}}$ TEq concentrations between the test samples from the Helsinki and Turku areas were found (Mann-Whitney $U$ test for $\mathrm{WHO}_{\mathrm{PCDD} / \mathrm{F}^{-}}-\mathrm{TEq}$ and $\mathrm{WHO}_{\mathrm{PCB}}-\mathrm{TEq}, p=0.70$ and $p=0.59$, respectively; Table 1).

There was no significant difference in $\mathrm{WHO}_{\mathrm{PCDD} / \mathrm{F}^{-T E q}}$ and $\mathrm{WHO}_{\mathrm{PCB}}-\mathrm{TEq}$ concentrations between test and control milk samples obtained from the Turku area (Mann-Whitney $U$ test

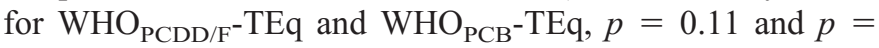
0.31 , respectively; Table 1 ).

Table 1. Dioxin toxic equivalents in mothers' milk samples

\begin{tabular}{|c|c|c|c|}
\hline & & $\mathrm{PCDD} / \mathrm{F}$ concentration & PCB concentration \\
\hline Milk samples & $n$ & $\begin{array}{c}\mathrm{WHO}_{\mathrm{PCDD} / \mathrm{F}^{-T E q}} \\
\mathrm{pg} / \mathrm{g} \text { fat } \\
\text { Median } \\
(25 \mathrm{th}-75 \mathrm{th} \\
\text { percentiles })\end{array}$ & $\begin{array}{c}\mathrm{WHO}_{\mathrm{PCB}^{-T E q ~} \mathrm{pg} / \mathrm{g} \text { fat }} \\
\text { Median } \\
\text { (25th-75th } \\
\text { percentiles) }\end{array}$ \\
\hline Test samples, total & 14 & $11.9(7.02-14.1)$ & $7.24(4.55-9.54)$ \\
\hline Helsinki area & 11 & $12.1(6.82-13.8)$ & $8.60(4.13-9.87)$ \\
\hline Turku area & 3 & $11.8(8.42-17.0)$ & $7.23(4.69-7.25)$ \\
\hline Controls, Turku area & 12 & $8.58(6.03-9.99)$ & $5.26(3.49-6.20)$ \\
\hline
\end{tabular}

Median dioxin toxic equivalent concentrations $\left(\mathrm{WHO}_{\mathrm{PCDD} / \mathrm{F}^{-T E q s}}\right.$ and $\mathrm{WHO}_{\mathrm{PCB}}-\mathrm{TEqs}$ ) and 25 th and 75 th percentiles in milk of mothers whose child had natal and neonatal teeth (test samples). The control samples were obtained from mothers whose child did not have natal and neonatal teeth. Samples were collected from the Helsinki and Turku areas located in southern Finland. 


\section{DISCUSSION}

Children born to mothers accidentally exposed to PCBs and $\mathrm{PCDD} /$ Fs have clearly had increased prevalences of natal teeth. In the Yusheng accident in Taiwan 13 of 128 transplacentally exposed newborns had natal teeth compared with none in the controls. The mothers had ingested rice-bran cooking oil that had been contaminated during manufacture with a mixture of PCB and PCDF compounds. A very similar accident, Yusho, took place in Japan $11 \mathrm{y}$ earlier, and increased numbers of children with natal teeth were reported there as well $(19,20)$. At birth the exposed children had also increased rates of eyelid swelling, nail deformity, swollen gums, oral hyperpigmentation, and acne.

The prevalence of natal and neonatal teeth in normal infants is much lower than in infants accidentally exposed to PCBs and PCDD/Fs. Theoretically, however, environmental toxicants could have affected the prevalence of natal and neonatal teeth because of their ubiquity. Our prevalence value of 1:1013 was at a similar level to those of studies including children who were born in the 1970 s or later $(3-5,11)$. Studies including children born in the 1960s and earlier showed lower prevalence figures (8).

If PCBs and PCDD/Fs were responsible for the increase in the prevalences of natal and neonatal teeth in the normal infant population, the changes in the environmental levels of these compounds should follow the changes in the prevalence figures. PCBs were manufactured from 1930 to 1970 s or 1980 s (varying in different countries), and the total production was in excess of a million metric tons. Input of $\mathrm{PCDD} / \mathrm{Fs}$ to the environment has been described as a pulse arising from human activities entering the environment in the 1930s and 1940s, peaking in the 1960s and 1970s, and continuing to a lesser degree today (25). The prevalence figures of natal and neonatal teeth are not in disagreement with the environmental levels of PCBs and PCDD/Fs. However, because of the limited number of epidemiologic studies on natal and neonatal teeth with sufficient populations and also because of the uncertainty of the exposure of humans to environmental toxicants before the discovery of proper analytical methods after 1985 (26), the relationship can only be speculated.

Developmental defects in the first permanent molars in Finnish children corresponded to their exposure to PCDD/Fs via mother's milk at the dioxin levels of 1987 (27). Our present findings of low PCBs and PCDD/Fs levels in milk of mothers who had children with natal or neonatal teeth was surprising. It did not support the hypothesis that environmental pollutants were associated with increased prevalences of natal and neonatal teeth. When compared with the levels found in human milk samples in Yusheng, it can be estimated that the Yusheng concentrations were 10-20 times higher for PCBs and 1001000 times higher for PCDFs. The present exposures may have been low enough not to cause premature eruption of teeth in infants.

During recent years there has been a sharp decline in PCDD/Fs and PCB concentrations in human milk in Europe. This has been demonstrated in a World Health Organizationcoordinated study in which PCB and PCDD/F levels in human milk has been systematically screened in 12 European countries including Finland (28). In Finland the decline can be explained mainly by a lowered dietary intake. A recent study showed that in our country the dietary intake level in 1999 was approximately half of the level in 1992 (29). Mothers' milk of the present children born in 1997-2000 contained lower levels of PCBs and PCDD/Fs than milk obtained from mothers of children born in 1987 or 1992 in the Helsinki area $(22,23)$. Accordingly, in our earlier studies the median $\mathrm{WHO}_{\mathrm{PCDD} / \mathrm{F}^{-}}$ TEq value in 1987 was $25.2 \mathrm{pg} / \mathrm{g}$ fat (77 samples) and in 1992, $19.7 \mathrm{pg} / \mathrm{g}$ (20 samples). The median value of $\mathrm{WHO}_{\mathrm{PCB}}-\mathrm{TEq}$ in 1987 was $25.5 \mathrm{pg} / \mathrm{g}$ fat and in 1992, $13.7 \mathrm{pg} / \mathrm{g}$ (Fig. 1) (22, 23). These groups of mothers had no children with natal or neonatal teeth. For a comparison, we calculated the prevailing levels (1999) in the Helsinki area from the milk concentrations analyzed in 1987 and 1992 by taking into account the decline of $25 \%$ for $\mathrm{WHO}_{\mathrm{PCDD} / \mathrm{F}^{-}}-\mathrm{TEq}$ and $50 \%$ for $\mathrm{WHO}_{\mathrm{PCB}}-\mathrm{TEq}$ and ended up with median $\mathrm{WHO}_{\mathrm{PCDD} / \mathrm{F}}-\mathrm{TEq}$ and $\mathrm{WHO}_{\mathrm{PCB}}-\mathrm{TEq}$ concentrations of $14.5 \mathrm{pg} / \mathrm{g}$ fat and $6.43 \mathrm{pg} / \mathrm{g}$, respectively. The $\mathrm{WHO}_{\mathrm{PCB}^{-}}-\mathrm{TEq}$ values in the Helsinki area in milk of mothers having a child with natal or neonatal teeth were thus at a slightly higher level, and $\mathrm{WHO}_{\mathrm{PCDD} / \mathrm{F}^{-}}-\mathrm{TEq}$ values at a slightly lower level, than the estimated values of these compounds in the same area.

Inasmuch as it was possible that the prevailing levels of environmental contaminants were different in the Turku and Helsinki areas, we handled these areas separately. However, no

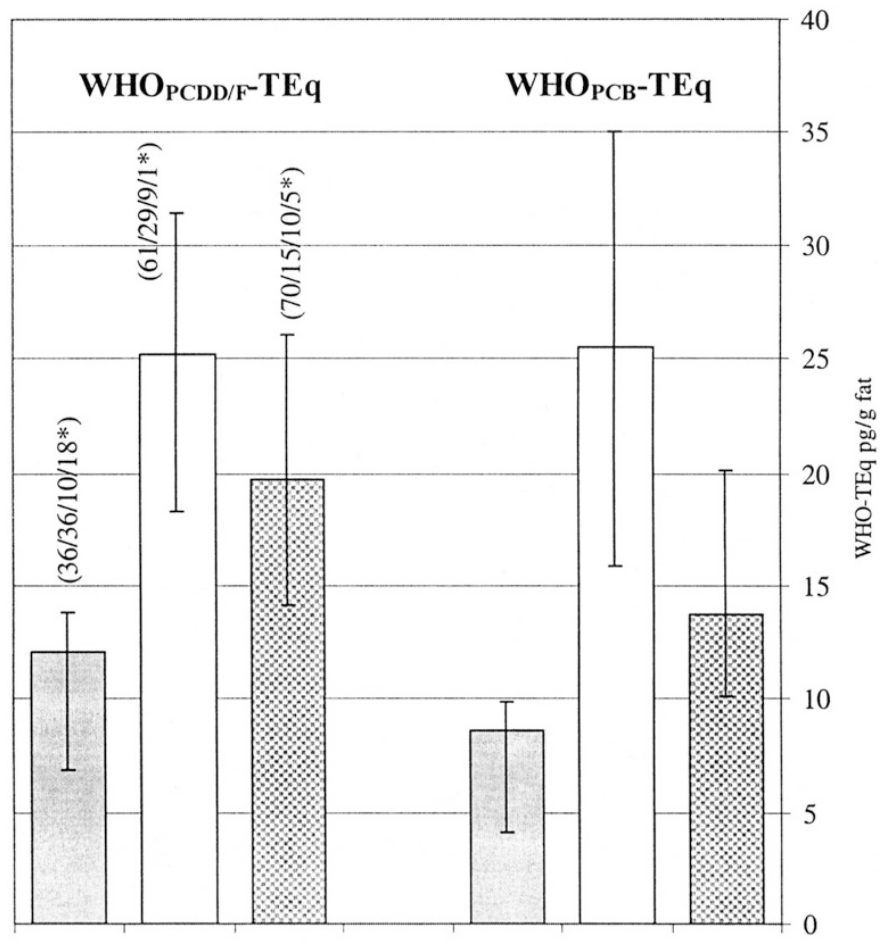

*Percentages of parities (1. child/2./3./4.)

Figure 1. Median concentrations (segment of a line indicating 25th and 75th

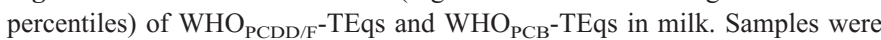
obtained from mothers whose children were born with natal or neonatal teeth in 1997-2000 in Helsinki ( $n=11$, dark gray bars) and from mothers whose children were born in 1987 ( $n=77$, white bars) and in 1992 ( $n=20$, stippled bars) but did not have natal and neonatal teeth. 
significant differences in the $\mathrm{WHO}_{\mathrm{PCDD} / \mathrm{F}^{-}}-\mathrm{TEq}$ and $\mathrm{WHO}_{\mathrm{PCB}}-$ TEq concentrations between natal and neonatal teeth and control milk samples obtained from the Turku area or between natal and neonatal milk samples obtained from the Helsinki and Turku areas were found. Preliminary unpublished measurements of $\mathrm{WHO}_{\mathrm{PCDD} / \mathrm{F}}-\mathrm{TEq}$ and $\mathrm{WHO}_{\mathrm{PCB}}-\mathrm{TEq}$ in the Helsinki area from samples collected in 2000-2001 follow quite closely our extrapolated concentrations, and they are also close to those obtained in the present study from the Turku area. In addition, a higher proportion of multiparous women were included in the present material compared with the previous measurements (Fig. 1). Levels of persistent organic pollutants decrease by lactation, and therefore toxicant levels in breast milk of multiparous women tend to be lower than in milk of nulliparous women. Taking this into account, the data thus seem to suggest that the concentrations seen in the test samples corresponded to the prevailing levels.

\section{CONCLUSION}

In summary, the results showed that the prevalence of natal and neonatal teeth was 1:1000. No association was found between the milk levels of PCDD/F and PCB compounds and the occurrence of natal and neonatal teeth, indicating that the prevailing levels of PCDD/Fs and PCBs are likely to be below the threshold to cause perinatal eruption of teeth.

\section{REFERENCES}

1. Massler M, Savara BS 1950 Natal and neonatal teeth: a review of twenty-four cases reported in the literature. J Pediatr 36:349-359

2. Allwright WC 1958 Natal and neonatal teeth: a study among Chinese in Hong Kong. Br Dent J 105:163

3. Kates GA, Needleman HL, Holmes LB 1984 Natal and neonatal teeth: a clinical study. J Am Dent Assoc 109:441-443

4. Bedi R, Yan SW 1990 The prevalence and clinical management of natal teeth-a study in Hong Kong. J Paediatr Dent 6:85-90

5. To EWH 1991 A study of natal teeth in Hong Kong. Int J Paediatr Dent 1:73-76

6. Bodenhoff J 1959 Natal and neonatal teeth. Odontol Tidskr 67:645-695

7. Zhu J, King D 1995 Natal and neonatal teeth. J Dent Child 62:123-128
8. Bodenhoff J, Gorlin RJ 1963 Natal and teeth: folklore and facts. Pediatrics 49:10871093

9. Rusmah M 1991 Natal and neonatal teeth: a clinical and histological study. J Clin Pediatr Dent 15:251-253

10. Mayhall JT 1967 Natal and neonatal teeth among the Tlinget Indians. J Dent Res 46:748-749

11. Leung AKC 1986 Natal teeth. Am J Dis Child 140:249-251

12. Boyd JD, Miles AEW 1951 Erupted teeth in a cyclops foetus. Br Dent J 91:173-181

13. Hals E $1957 \mathrm{Natal}$ and neonatal teeth: histologic investigations in two brothers. Oral Surg 10:509-521

14. Huisman M, Koopman-Esseboom C, Fidler V 1995 Perinatal exposure to polychlorinated biphenyls and dioxins and its effect on neonatal neurological development. Early Hum Dev 41:111-127

15. Lackmann GM, Göen T, Töllner U, Schaller KH, Angerer J 1996 PCBs and HCB in serum of full-term German neonates. Lancet 348:1035

16. Koppe JG, Olie K, van Wijnen J 1992 Placental transport of dioxins from mother to fetus. II. PCBs, dioxins and furans and vitamin K metabolism. Dev Pharmacol Ther 18:9-13

17. Rogan WJ, Gladen BC, Hung K-L 1988 Congenital poisoning by polychlorinated biphenyls and their contaminants in Taiwan. Science 241:334-336

18. Gladen BC, Taylor JS, Wu Y-C, Beth Ragan N, Rogan WJ, Hsu C-C 1990 Dermatological findings in children exposed transplacentally to heat-degradated polychlorinated biphenyls in Taiwan. Br J Dermatol 122:799-808

19. Funatsu I, Yamashita F, Yoshita F 1971 A chlorophenyl induced fetopathy. Fukuoka Acta Med 62:139-149

20. Yamaguchi A, Yoshimura T, Kuratsune M 1971 A survey on pregnant women having consumed rice oil contaminated with chlorobiphenyls and their babies. Fukuoka Acta Med 62:117-122

21. Madhukar BV, Brewster DW, Matsumura F 1984 Effect of in vivo-administered 2,3,7,8-tetrachlorodibenzo- $p$-dioxin on receptor binding of epidermal growth factor in the hepatic plasma membrane of rat, guinea pig, mouse and hamster. Proc Natl Acad Sci USA 81:7407-7411

22. Vartiainen T, Saarikoski S, Jaakkola JJ, Tuomisto J 1997 PCDD, PCDF, and PCB concentrations in human milk from two areas in Finland. Chemosphere 34:2571-2583

23. Kiviranta H, Purkunen R, Vartiainen T 1999 Levels and trends of PCDDs and PCBs in human milk in Finland. Chemosphere 38:311-323

24. Van der Berg M, Birnbaum L, Bosveld ATC 1998 Toxic equivalency factors (TEFs) for PCBs PCDDs, PCDFs for humans and wildlife. Environ Health Perspect 106:775792

25. Alcock RE, Jones KC 1996 Dioxins in the environment: a review of trend data. Environ Sci Technol 30:3133-3143

26. Rappe C, Marklund S, Kjeller L-O, Bergqvist P-A, Hansson M 1985 Strategies and techniques for sample collection and analysis: experiences from the Swedish PCB accidents. Environ Health Perspect 60:279-292

27. Alaluusua S, Lukinmaa P-L, Torppa J, Tuomisto J, Vartiainen T 1999 Developing teeth as biomarker of dioxin exposure. Lancet 353:206

28. WHO/ECEH (World Health Organization/European Centre for Environmental and Health) 1996 Levels of PCBs, PCDDs and PCDFs in human milk: second round of WHO-coordinated exposure study. Environmental Health in Europe 3. WHO, European Centre for Environmental and Health, Bilthoven-Copenhagen-Nancy-Rome

29. Kiviranta H, Hallikainen A, Ovaskainen M-L, Kumpulainen J, Vartiainen T 2001 Dietary intakes of polychlorinated dibenzo- $p$-dioxins, dibenzofurans and polychlorinated biphenyls in Finland. Food Addit Contam 18:945-953 